\title{
Article \\ Electrochemical Performance Enhancement of Micro-Sized Porous Si by Integrating with Nano-Sn and Carbonaceous Materials
}

\author{
Tiantian Yang, Hangjun Ying *(D), Shunlong Zhang, Jianli Wang, Zhao Zhang and Wei-Qiang Han *(D) \\ School of Materials Science and Engineering, Zhejiang University, Hangzhou 310027, China; \\ dayday_y@foxmail.com (T.Y.); zhangshunlong@zju.edu.cn (S.Z.); 11726038@zju.edu.cn (J.W.); \\ 11826056@zju.edu.cn (Z.Z.) \\ * Correspondence: yinghangjun@zju.edu.cn (H.Y.); hanwq@zju.edu.cn (W.-Q.H.)
}

check for updates

Citation: Yang, T.; Ying, H.; Zhang, S.; Wang, J.; Zhang, Z.; Han, W.-Q. Electrochemical Performance Enhancement of Micro-Sized Porous Si by Integrating with Nano-Sn and Carbonaceous Materials. Materials 2021, 14, 920. https://doi.org/ $10.3390 /$ ma14040920

Academic Editor: Digby Macdonald Received: 11 January 2021

Accepted: 5 February 2021

Published: 15 February 2021

Publisher's Note: MDPI stays neutral with regard to jurisdictional claims in published maps and institutional affiliations.

Copyright: (c) 2021 by the authors. Licensee MDPI, Basel, Switzerland. This article is an open access article distributed under the terms and conditions of the Creative Commons Attribution (CC BY) license (https:// creativecommons.org/licenses/by/ $4.0 /)$.

\begin{abstract}
Silicon is investigated as one of the most prospective anode materials for next generation lithium ion batteries due to its superior theoretical capacity $\left(3580 \mathrm{mAh} \mathrm{g}^{-1}\right)$, but its commercial application is hindered by its inferior dynamic property and poor cyclic performance. Herein, we presented a facile method for preparing silicon/tin@graphite-amorphous carbon (Si/Sn@G-C) composite through hydrolyzing of $\mathrm{SnCl}_{2}$ on etched $\mathrm{Fe}-\mathrm{Si}$ alloys, followed by ball milling mixture and carbon pyrolysis reduction processes. Structural characterization indicates that the nano-Sn decorated porous Si particles are coated by graphite and amorphous carbon. The addition of nano-Sn and carbonaceous materials can effectively improve the dynamic performance and the structure stability of the composite. As a result, it exhibits an initial columbic efficiency of $79 \%$ and a stable specific capacity of $825.5 \mathrm{mAh} \mathrm{g}^{-1}$ after 300 cycles at a current density of $1 \mathrm{~A} \mathrm{~g}^{-1}$. Besides, the $\mathrm{Si} / \mathrm{Sn} @ \mathrm{G}-\mathrm{C}$ composite exerts enhanced rate performance with $445 \mathrm{mAh} \mathrm{g}^{-1}$ retention at $5 \mathrm{~A} \mathrm{~g}^{-1}$. This work provides an approach to improve the electrochemical performance of $\mathrm{Si}$ anode materials through reasonable compositing with elements from the same family.
\end{abstract}

Keywords: Si/Sn@G-C composite; Lithium-ion battery; tin; porous silicon; anode material

\section{Introduction}

Lithium-ion batteries (LIBs) affect many aspects of our lives because of their high energy density, low self-discharge rate and good rate capacity [1-3]. However, the development of related equipment puts forward higher requirements for the performance of LIBs [4-10]. Graphite has been used in LIBs as anode material for decades because of its stable capacity retention, but its theoretical capacity of $372 \mathrm{mAh} \mathrm{g}{ }^{-1}$ limits the further development of LIBs with higher energy density and security [11-14].Therefore, much efforts have been devoted to develop new anode materials, such as Si [15], Sn [16] and metal oxides [17-23]. Among all the candidates, silicon with high specific capacity (3580 mAh g ${ }^{-1}$ ) [24], moderate operation potential (around $0.4 \mathrm{~V} \mathrm{vs.} \mathrm{Li} / \mathrm{Li}^{+}$), environmentally benign nature and abundant reserves is considered as one of the most promising next generation anode materials $[25,26]$. Despite these advantages, some defects prevent silicon anode from being widely used: its low electronic conductivity $\left(2 \times 10^{3} \Omega \cdot \mathrm{m}\right)$ and structural instability upon lithiation result in inferior rate performance and rapid capacity fading [27].

In order to alleviate the huge change in the volume during cycles and increase the electrical conductivity of $\mathrm{Si}$, several approaches have been discussed, including constructing different structures of silicon and designing Si-based composites [28]. Various silicon-based nanostructures have been proposed, such as nanoparticles [29-31], nanowires [32-34], porous structures [35-37], yolk-shell constructions [38]. These structures exhibit good structural stability, fast ion diffusion path and led to ideal electrochemical performance, but most of them lack potential of commercial application because of the high cost of the 
methodology or the inability to large-scale preparation [39]. The micro-sized porous $\mathrm{Si}$ with high performance has exhibited hopeful prospect of practical application and scalable production [12].

Reasonable compositing modification is also an important way to promote the electrochemical behavior of Si anode materials. [40-43]. For example, Yang [16] synthesized a Si/Sn@C-G composite by the method of high energy ball milling and annealing, the composite shows stable reversible capacity of $612.6 \mathrm{mAh} \mathrm{g}^{-1}$ at a current density of $1 \mathrm{~A} \mathrm{~g} \mathrm{~g}^{-1}$ and a high initial columbic efficiency of $81.5 \%$. Zhong et al. [44] used nano-sized silicon particles, tin dichloride and PVP to synthesize a Si/Sn@C anode that has good electrochemical performance. Yang et al. [39] prepared a Si/C-G anode by the way of ball milling and carbon pyrolyzing, the composite has a capacity of $445 \mathrm{mAh} \mathrm{g}^{-1}$ at a current density of $0.5 \mathrm{~A} \mathrm{~g}^{-1}$ with a high capacity retention after 200 cycles. In addition, the way of combining $\mathrm{Si}$ with other active or inactive metals (such as Sn [35], Co [45,46], Ag [47-49], Ni [50], $\mathrm{Cu}$ [51-53], et. al.) has also been widely reported for LIBs. Hao et al. [35] fabricated hierarchical macroporous $\mathrm{Si} / \mathrm{Sn}$ composites via facile and green dealloying process by etching $\mathrm{SiSnAl}$ alloy precursors, the composite delivers a capacity of $1600 \mathrm{mAh} \mathrm{g}^{-1}$ at $200 \mathrm{~mA} \mathrm{~g}^{-1}$ in the period of 70 cycles. Zhao et al. [54] synthesized an Ag-Si core-shell nanowall arrays by displacement reaction and subsequent RF-sputtering deposition, the composite shows a specific capacity of $1500 \mathrm{mAh} \mathrm{g}^{-1}$ at $2100 \mathrm{~mA} \mathrm{~g}^{-1}$. Li et al. [55] fabricated a Si-Cu composite by etching and electroless plating, the composite presents a specific capacity of $1651 \mathrm{mAh} \mathrm{g}^{-1}$ after 150 cycles with a columbic efficiency of $99 \%$. Although many attainments have been achieved in the development of Si anode materials, a facial and low-cost modification way is still desired [56,57]. The metallic $\mathrm{Sn}$ in the same group has similar lithiation mechanism and electrochemical potentials with that of $\mathrm{Si}$, and shows much better electro conductibility $[58,59]$. Hence, Sn can work as an efficient agent to improve the kinetic properties of Si. Herein, we design and synthesize silicon/tin@graphite-amorphous carbon (Si/Sn@G-C) composites and assesse their performance as anode for LIBs. The reasonably designed ternary composites exhibit enhanced performance than the contrast samples, which may result from the kinetic improvement and structural reinforcement of nano-Sn and composited carbon.

\section{Materials and Methods}

\subsection{Material Preparation}

Micro-sized porous silicon: the silicon particles are prepared by the way of etching Fe-Si alloy, similar to our previous report [60]. The obtained micro-sized porous silicon presents a unique hierarchical pore structure with coexisting micro-meso-macropores. The specific surface area of as-synthesized micro-sized porous silicon is $17.1 \mathrm{~m}^{2} \mathrm{~g}^{-1}$ (calculated from BET data).

Si/Sn@G-C,Si@G-C and Si/Sn@G composite: micro-sized porous silicon, artificial graphite ( $>99.5 \%$, Xianding Biological Technology Co., Ltd., Shanghai, China), stannic chloride (99\%, Alfa Aesar, Haverhill, MA, USA), polyvinyl alcohol (molar weight 31,000, Aladdin, China), are used as raw materials for the synthesis of the $\mathrm{Si} / \mathrm{Sn} @ \mathrm{G}-\mathrm{C}$ composites. Typically, $0.4 \mathrm{~g}$ micro-sized porous silicon and $0.1 \mathrm{~g} \mathrm{SnCl} 2 \cdot 2 \mathrm{H}_{2} \mathrm{O}$ are weighted and added into $20 \mathrm{~mL}$ distilled $\mathrm{H}_{2} \mathrm{O}$ and magnetic stirred for $60 \mathrm{~min}$ at room temperature. The treated silicon particles are then rinsed with distilled $\mathrm{H}_{2} \mathrm{O}$ and treated through filtering. The particles obtained are further ball milled with graphite and the polyvinyl alcohol with a weight ratio of 4:4:2 at $400 \mathrm{rpm}$ for $5 \mathrm{~h}$ in a ball mill machine (PM200, Retsch GmbH Inc., Haan, Germany), the weight ratio of milling balls to mixture is 20:1. Finally, the mixture above is pyrolyzed in a tube furnace (BTF-1200C, BEQ Equipment Technology Co., Ltd., Anhui, China) at $750{ }^{\circ} \mathrm{C}$ for $3 \mathrm{~h}\left(\mathrm{Ar}, 100 \mathrm{~mL} \mathrm{~min}{ }^{-1}\right)$ to obtain the Si/Sn@G-C products. The composite treated by the same processes without $\mathrm{SnCl}_{2}$ is named $\mathrm{Si} @ \mathrm{G}-\mathrm{C}$ and the composite prepared without polyvinyl alcohol is called Si/Sn@G. 


\subsection{Material Preparation}

The morphology of the composites is observed by the scanning electron microscopy (SU-8100, Hitachi Manufacturing Co., Ltd., Tokyo, Japan), equipped with an energy dispersive spectroscopy system. The X-ray diffractometer (XRD-6000, Shimadzu Co., Ltd., Tokyo, Japan) with a $\mathrm{Cu} \mathrm{K} \alpha$ radiation source (radiation $=0.154 \mathrm{~nm}, 2 \theta=10^{\circ} \sim 90^{\circ}$ ) and the Raman spectrum are used to analyze the composition of the as prepared materials, which is operated on a Renish in Via Raman system and the Raman shifts are collected in the range of 1000 $2000 \mathrm{~cm}^{-1}$. The pore size distribution and the surface area of the composites is evaluated by the analysis of nitrogen adsorption-desorption data on an ASAP 2020M (Micromeritics Instrument Corp., Norcross, GA, USA). Thermogravimetric analysis (TGA) was carried out using Perkin Elmer Diamond TG/DTA (Perkin Elmer Co., Ltd, Waltham, Massachusetts, USA) instrument at a heating rate of $10^{\circ} \mathrm{C} \mathrm{min}^{-1}$ from $20^{\circ} \mathrm{C}$ to $900{ }^{\circ} \mathrm{C}$ under air.

\subsection{Electrochemistry Measurements}

To measure the electrochemical performance of the obtained sample, an aqueous slurry contains the active materials, carboxyl methyl cellulose (Aldrich, Shanghai, China) and carbon black (Alfa Aesar, Haverhill, MA, USA) with the weight ratio of 8:1:1 is prepared. The slurry is stirred for over $6 \mathrm{~h}$ and uniformly casted onto a thin copper foil ( $40 \mathrm{~mm} \times$ $100 \mathrm{~mm}$ ) and dried in vacuum at $70^{\circ} \mathrm{C}$ for $12 \mathrm{~h}$. Then the film is punched into circular discs for the future fabrication. The coin-type cells are assembled with lithium foil as the counter electrode, a poly-propylene film (Celgard-2400) as the separator and $1 \mathrm{M} \mathrm{LiPF}_{6}$ solution in a mixture of dimethyl carbonate(DMC), fluoroethylene carbonate (FEC), and ethyl methyl carbonate(EMC) as the electrolyte (DMC/FEC/EMC, 1:1:1 in volume, Shanshan Battery Material Co., Ltd., Dongguan, China). The coin cells are assembled in an argon-filled glove box (Mikrouna, China). The cells are charged and discharged on a LAND instrument (Lanhe-CT3100A, Wuhan Landian Electronics Co., Ltd., China) within the voltage range of $0.1 \sim 1.2 \mathrm{~V}$. The cyclic voltammogram (CV) is carried out at a scan rate of $0.1 \mathrm{mV} \mathrm{s}^{-1}$ within a potential range of $0.01 \sim 1.5 \mathrm{~V} \mathrm{vs}$. $\mathrm{Li} / \mathrm{Li}^{+}$. The EIS measurement is carried out at open circuit potential over the frequency range from $0.01 \mathrm{~Hz}$ to $100 \mathrm{kHz}$ with an amplitude of $5 \mathrm{mV}$. The CV and EIS are measured by an electrochemical workstation (Solartron-1470E, AMETEK, Inc., Champaign, IL, USA).

\section{Result and Discussion}

Figure 1 shows the preparation scheme, XRD patterns and Raman spectra of the sample, respectively. As shown in Figure $1 \mathrm{~b}$ and Figure S1a, as-prepared porous Si and $\mathrm{Si} / \mathrm{Sn} @ \mathrm{G}-\mathrm{C}$ exhibits a series of diffraction peaks, in which the relative strong peaks around $2 \theta=28.4^{\circ}, 47.3^{\circ}, 56.1^{\circ}, 73.3^{\circ}, 88.0^{\circ}$ can be assigned to the (111), (220), (311), (331) and (422) planes of $\mathrm{Si}(\mathrm{PDF} 27-1402)$, while diffraction peaks at $2 \theta=30.6^{\circ}, 32.0^{\circ}, 43.9^{\circ}, 44.9^{\circ}$, $55.3^{\circ}, 62.5^{\circ}, 63.8^{\circ}, 64.6^{\circ}$ and $72.4^{\circ}$ in Si/Sn@G-C are corresponded to the (200), (101), (220), (211), (301), (112), (400), (321) and (420) planes of Sn, suggesting the successful decoration of nano-Sn on porous Si. Several peaks at $2 \theta=26.4^{\circ}, 44.4^{\circ}$ belong to the (002) and (101) planes of the graphite (PDF\#41-1487) (Figure S1b). According to the TGA test, whose result is presented in Figure S2, the content of carbon in $\mathrm{Si} / \mathrm{Sn} @ \mathrm{G}-\mathrm{C}$ composite is $53.2 \mathrm{wt} . \%$. The XRD results of other composites (Si/Sn, Si@G-C and Si/Sn@G) are shown in Figure S3 All these evidences suggest the $\mathrm{Si} / \mathrm{Sn} @ \mathrm{G}-\mathrm{C}$ composite is successfully prepared.

The Raman spectra are recorded in Figure 1c, all the composites have two peaks (ca. $1342 \mathrm{~cm}^{-1}$ and $1589 \mathrm{~cm}^{-1}$ ), which are the D and G bands of carbon materials, respectively. The D-band is related to the disordered structure of carbon and always can be found in amorphous or disorder carbon, while G-band reflects the bond stretching of the $\mathrm{sp}^{2}$ carbon atoms [61]. The ratio of $\mathrm{I}_{\mathrm{D}}$ to $\mathrm{I}_{\mathrm{G}}\left(\mathrm{I}_{\mathrm{D}}: \mathrm{I}_{\mathrm{G}}\right)$ indicates the graphitization extent of materials, a low $\mathrm{I}_{\mathrm{D}}: \mathrm{I}_{\mathrm{G}}$ implies a high extent of graphitization. With the addition of amorphous carbon, the $\mathrm{I}_{\mathrm{D}}: \mathrm{I}_{\mathrm{G}}$ ratio increases, which means the decrease of graphitization extent of Si/Sn@G-C 
in comparison to Si/Sn@G. Besides, the result shows that the presence of Sn has little effect on the graphitization degree.

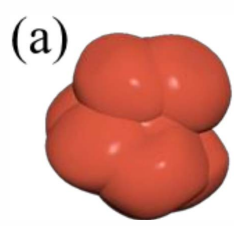

Fe-Si alloy (i) Ball milling (ii) Acid etching Micro-sized
porous $\mathrm{Si}$

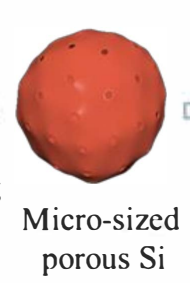

(b)

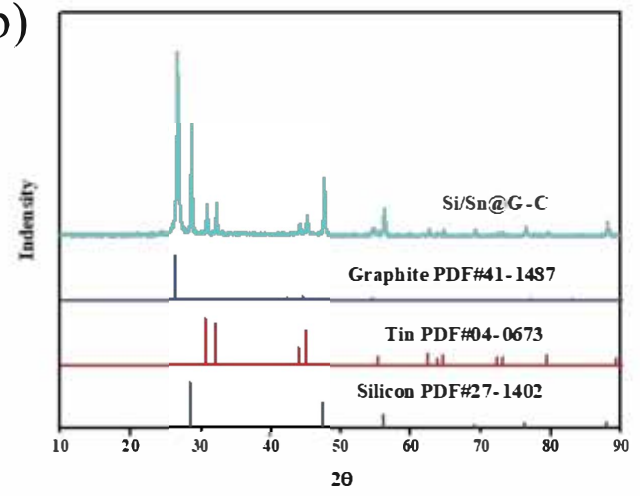

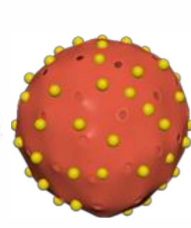

Graphite \& PVA

(i) Ball milling

(ii) Pyrolyzing

$\mathrm{Si} / \mathrm{Sn}$ composite

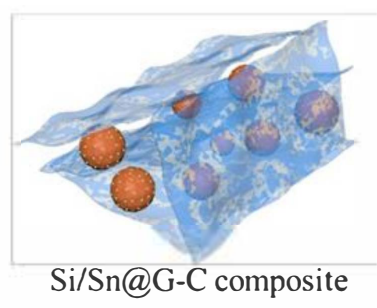

(c)

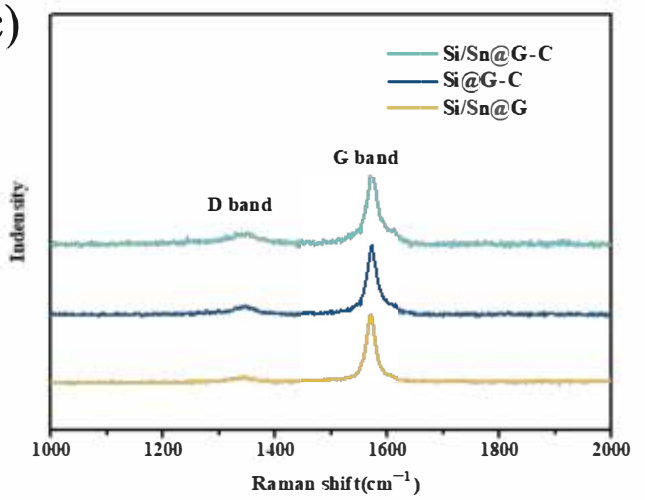

Figure 1. (a) Preparation process of Si/Sn@G-C composite; (b) XRD pattern of Si/Sn@G-C composite; (c) Raman spectrum of the composites.

We use the scanning electron microscopy (SEM) to collect the morphology information of materials, the top-down SEM images of the composites and the EDS result of Si/Sn@G-C composite are shown in Figure 2, and the element content obtained by EDS is presented in Table S2. Figure 2a and Figure S4a-d reveal the SEM images of the micro-sized porous Si and the graphite. As shown in Figure 2a, the silicon shows particle size with micro-scale, without obvious agglomeration. It is indicated in Figure S4a,b, the particle size of artificial graphite is around $10 \mu \mathrm{m}$. Figure $2 \mathrm{~b}-\mathrm{e}$ and Figure S4e,f are the SEM images of Si@G-C, Si/Sn@G and Si/Sn@G-C composites, respectively. Figure 2d,e show typical SEM images of Si/Sn@G-C composite, it is observed that the graphite undergoes fierce breakage during ball milling. According to the element mapping in Figure $2 \mathrm{f}-\mathrm{i}$, the $\mathrm{Si}, \mathrm{Sn}$ and C elements distribute uniformly in the composite, suggesting the components of Si/Sn@G-C composite are evenly mixed. The SEM image of the Si@G-C composite (Figure $2 b$ ) is similar to that of Si/Sn@G-C because the hydrolyzed Sn particles are small in size and attached to the surface of Si and cannot be easily found in SEM image [62]. The existence of nano-Sn has been proved by the XRD and SEM-EDS. As shown in Figure 2c, the amorphous carbon can effectively encapsulate the $\mathrm{Si} / \mathrm{Sn}$ nanoparticles within it. It is reported that the addition of amorphous carbon on the surface of the composite will prevent the silicon particles from separation by providing effective constrain force and is beneficial for the electronic transmission, so it can improve the electrochemical performance of the material [63].

The transmission electron microscope (TEM) is used to get more detailed information about the morphology and structure of the composite, and the result is given in Figure 3. As shown in Figure 3a, the Si/Sn@G-C is composed of carbon outerwear and grain kernel. Figure 3b-e show the HRTEM images and the selected area electron diffraction (SAED) pattern of the composite, from which we can clearly distinguish the different components of the composite. The amorphous carbon is around 6-10 nm in thickness, integrated with graphitized carbon and performs as outerwear to encapsulate the active particles within the carbon layer. It is seen that the Sn nanoparticles disperse on the surface of Si strains, which would act as transmission sites to contribute to the transmission of electrons and enhance the conductivity of the composite. 

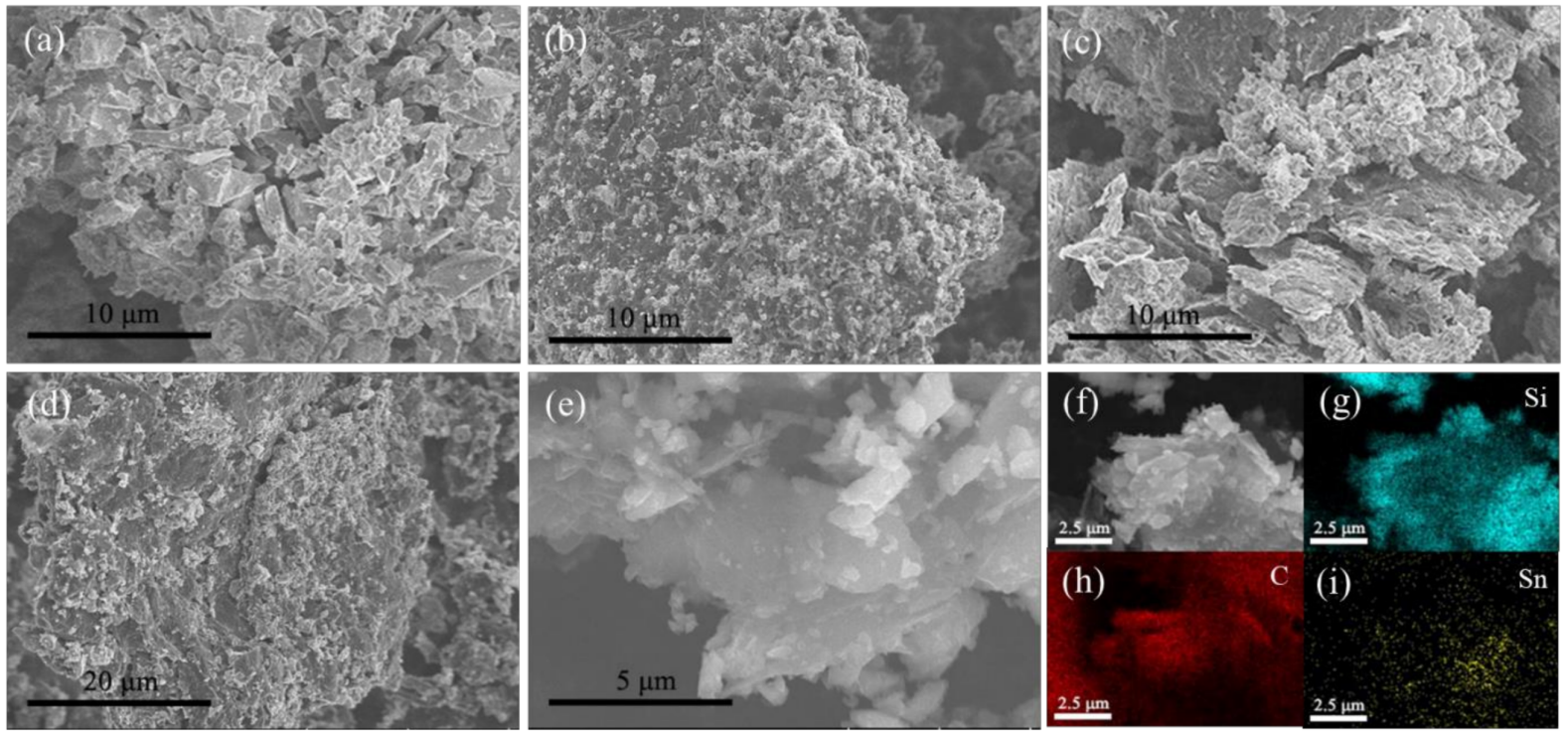

Figure 2. The SEM images of (a) micro-sized porous Si, (b) Si@G-C composite, (c) Si/Sn@G composite, (d,e) Si/Sn@G-C composite, (f-i) EDS result of Si/Sn@G-C composite.
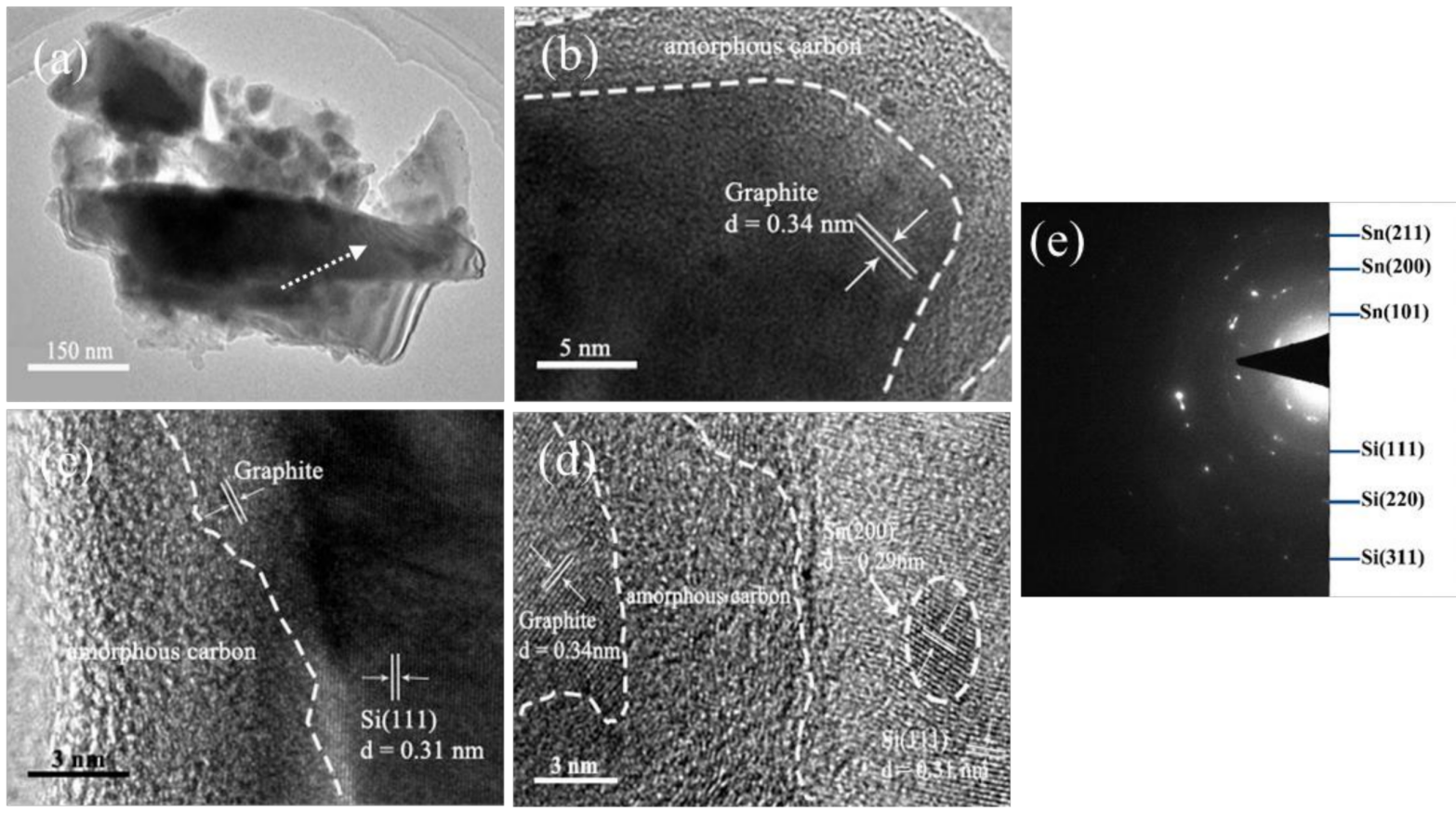

Figure 3. TEM and HRTEM pictures of the Si/Sn@G-C composite. (a) TEM image, (b-d) HRTEM images, (e) SAED pattern of the zone arrowed in (a).

In order to evaluate the specific surface area and pore distribution of the composites, BET is implemented and the result is given in Figure 4, and Figures S5 and S6. It is proved that the specific surface area of porous $\mathrm{Si}$ and $\mathrm{Si} / \mathrm{Sn} @ \mathrm{G}-\mathrm{C}$ composite are 17.1 and $26.4 \mathrm{~m}^{2} \mathrm{~g}^{-1}$, respectively. The $\mathrm{N}_{2}$ isothermal absorption and desorption curves show the type-IV adsorption of both $\mathrm{Si} / \mathrm{Sn} @ \mathrm{G}-\mathrm{C}$ and porous $\mathrm{Si}$, which indicates the presence of macropores and mesopores. Figure $4 \mathrm{~b}$ presents the pore size distribution of porous $\mathrm{Si}$ and the Si/Sn@G-C composite, verifying the existence of macropores and mesopores. Although the specific surface area of Si/Sn@G-C is larger in comparison to porous $\mathrm{Si}$, the micropores are effectively controlled during the compositing process, which can restrain the irreversible $\mathrm{Li}^{+}$insertion in the micropores. More mesopores and macropores in the 
composite can promote electrolyte infiltration and is favorable for the transmission of lithium ions, therefore the rate performance of the material is improved [39]. Besides, these pores can relive the huge volume change of $\mathrm{Si}$ anode during cycles, resulting in good long-term cycling stability. The BET result of Si@G-C and Si/Sn@G is given in Figures S5 and S6, respectively. These composites show the same adsorption type and similar pore size distribution with $\mathrm{Si} / \mathrm{Sn} @ \mathrm{G}-\mathrm{C}$, the specific surface area is $25.8 \mathrm{~m}^{2} \mathrm{~g}^{-1}$ and $23.3 \mathrm{~m}^{2} \mathrm{~g}^{-1}$ for Si/Sn@G and Si@G-C, respectively.
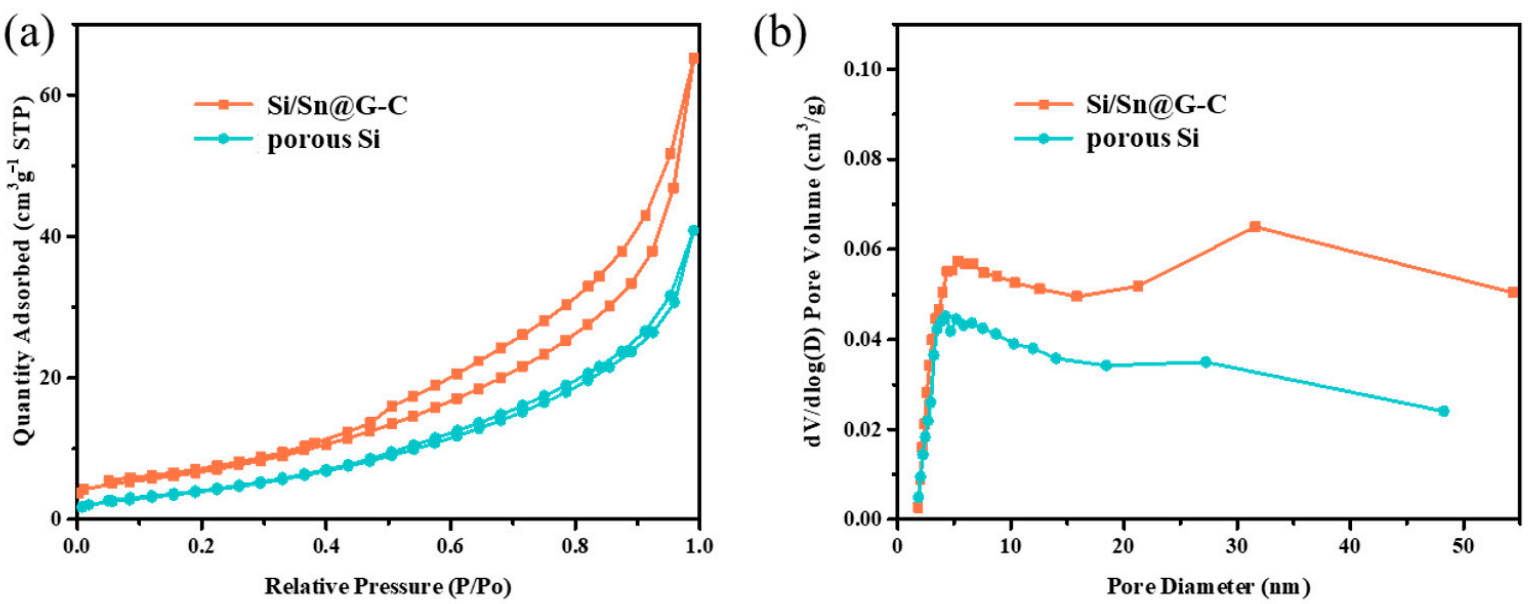

Figure 4. The BET results of the Si/Sn@G-C composite (a) the $\mathrm{N}_{2}$ adsorption/desorption isotherm and (b) pore size distribution.

The electrochemical performance of the composites and porous $\mathrm{Si}$ is fully evaluated and shown in Figure 5, and Figures S7 and S8. Figure 5a shows the charging/discharging curves of Si/Sn@G-C composite for the 1st, 20th, 100th and 300th cycles at $1 \mathrm{~A} \mathrm{~g}^{-1}$ within the potential range of $0.01-1.2 \mathrm{~V}$ (vs. $\mathrm{Li} / \mathrm{Li}^{+}$). The composite has an initial discharge capacity of $1425.5 \mathrm{mAh}^{-1}$ with an initial columbic efficiency (ICE) of $79 \%$ and the irreversible specific capacity is $299.9 \mathrm{mAh}^{-1}$, which is mainly caused by the formation of solid electrolyte interface (SEI) [64]. It is indicated by Figure 5a that the reversible specific capacity remains $1176 \mathrm{mAh} \mathrm{g}^{-1}$ after 100 cycles, corresponding to 83\% capacity retention relative to the first cycle, and even after 300 cycles, the composite still exhibits obvious electrochemical platform with slight polarization voltage.

Figure $5 c$ reveals the cycle performance of Si/Sn@G-C composite at $500 \mathrm{~mA} \mathrm{~g}^{-1}$ in the potential of $0.01-1.2 \mathrm{~V}$. It is indicated that the composite presents a specific discharge capacity of $1013.3 \mathrm{~mA} \mathrm{~g}^{-1}$ after 100 cycles with high capacity retention (92\%). Figure $5 \mathrm{~d}$ compares the circulation properties of the composites at $1 \mathrm{~A} \mathrm{~g}^{-1}$. The Si/Sn@G-C composite shows the best cycle performance among all the samples, whose specific discharge capacity remains $825.5 \mathrm{mAh} \mathrm{g}^{-1}$ after 300 cycles, while Si@G-C and Si/Sn@G remains 588.8 and $559.4 \mathrm{mAh}^{-1}$, respectively. The best cycle performance of $\mathrm{Si} / \mathrm{Sn} @ \mathrm{G}-\mathrm{C}$ may result from the structural and kinetic reinforcing role of amorphous carbon and nano-Sn. The rate performance of the prepared composites is displayed in Figure $5 b$, the charge capacity of $\mathrm{Si} / \mathrm{Sn} @ \mathrm{G}-\mathrm{C}$ is $1278,1273,1197,1094,940$, and $709 \mathrm{mAh} \mathrm{g}^{-1}$ at $0.05,0.1,0.2,0.5,1,2$ and $5 \mathrm{~A} \mathrm{~g}^{-1}$, respectively. Once the current density returns to $0.2 \mathrm{~mA} \mathrm{~g}^{-1}$, the specific capacity

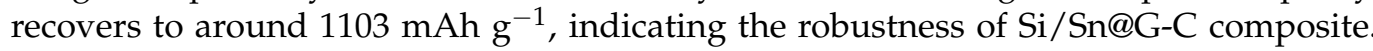
The result reveals that after the addition of $\mathrm{Sn}$ and amorphous carbon, the cycle and rate performance of the composite has been significantly improved. That is because $\mathrm{Sn}$ can improve the conductivity of the composite, enables the full utilization of the active material and the amorphous carbon can work as bridging agent, prevents the silicon particles from separation by provide effective constrain force $[39,44]$. We also compare the performance of the Si/Sn@G-C composite with other electrodes based on similar materials (Figure S1), it is obvious that the cycle performance or the ICE of the as prepared sample is not the most prominent, but the sample has good overall performance. 

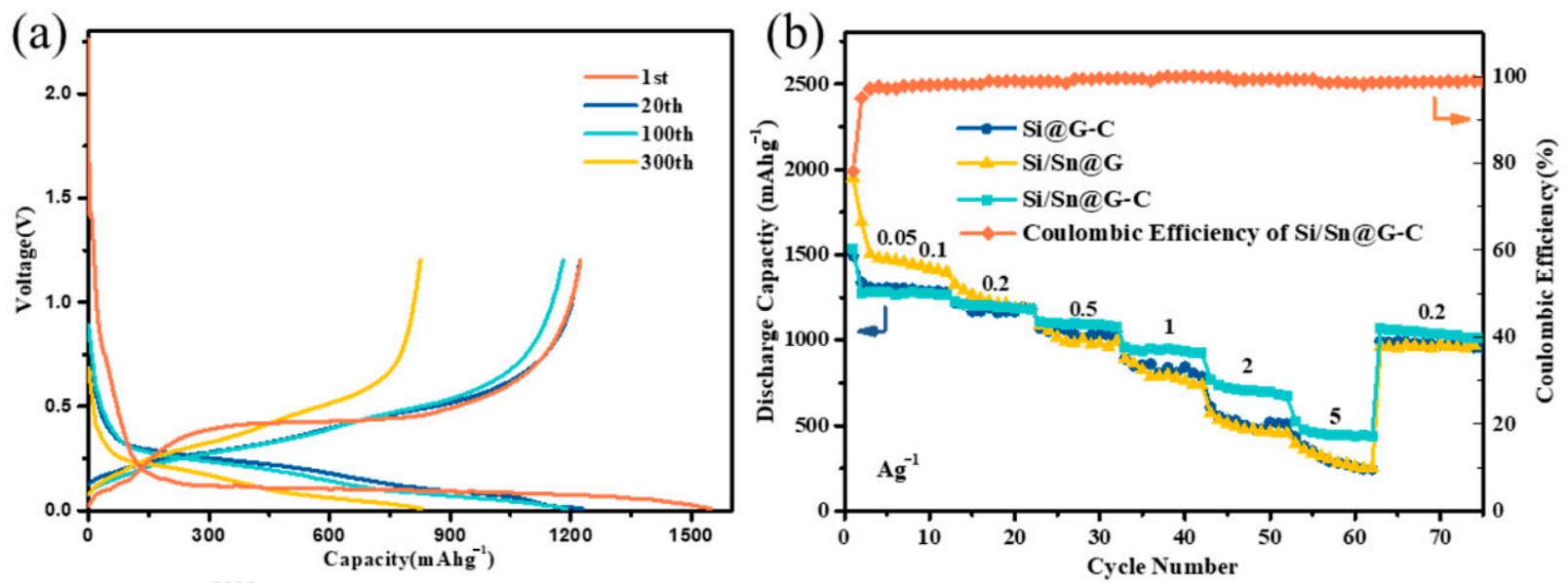

(c)
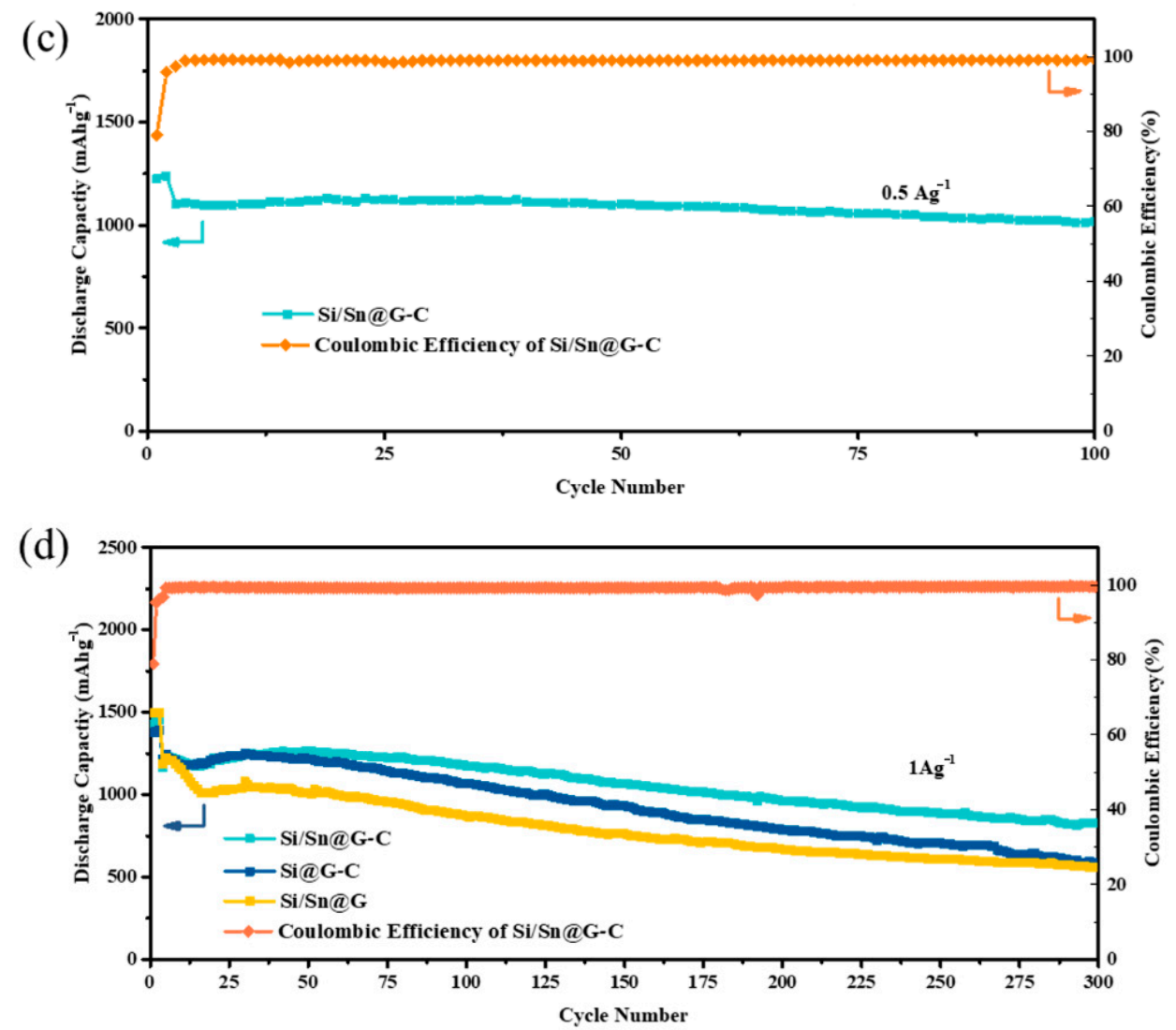

Figure 5. Electrochemical performance of as-prepared samples: (a) the charging/discharging voltage profiles of the Si/Sn@G-C anode for the 1st, 20th, 100th and 300th cycles; (b) rate performance of the Si/Sn@G-C anode; (c) cycle performance of the Si/Sn@G-C anode at $0.5 \mathrm{~A} \mathrm{~g}^{-1}$ in 100 cycles, (d) cycling performance of Si/Sn@G-C, Si@G-C and $\mathrm{Si} / \mathrm{Sn} @ \mathrm{G}$ anodes at $1 \mathrm{~A} \mathrm{~g}^{-1}$.

The CV curves of the composites within the voltage of $0.01-1.5 \mathrm{~V}$ are depicted in Figure $6 \mathrm{a}-\mathrm{c}$. The measurements are performed at a sweep rate of $0.1 \mathrm{mV} \mathrm{s}^{-1}$. For the $\mathrm{Si} / \mathrm{Sn} @ \mathrm{G}-\mathrm{C}$ composite, a clear reduction peak at $0.2 \mathrm{~V}$ and oxidation peaks at $0.32 \mathrm{~V}$ and $0.48 \mathrm{~V}$ can be observed and can be attributed to the silicon alloying/dealloying reactions with $\mathrm{Li}^{+}$(Figure 6a) [16]. The lithiation/delithiation peaks of nano-Sn are unobservable in the CV curves because of the low content and ultrafine particle size of Sn [44]. The intensity of the peaks increases gradually in the following cycles, indicating a gradual activation process of Si-based materials. Figure $6 \mathrm{~b}, \mathrm{c}$ display the CV curves of the $\mathrm{Si} / \mathrm{Sn} @ \mathrm{G}$ and Si@G-C composites, which exhibit similar CV peaks with Si/Sn@G-C. 

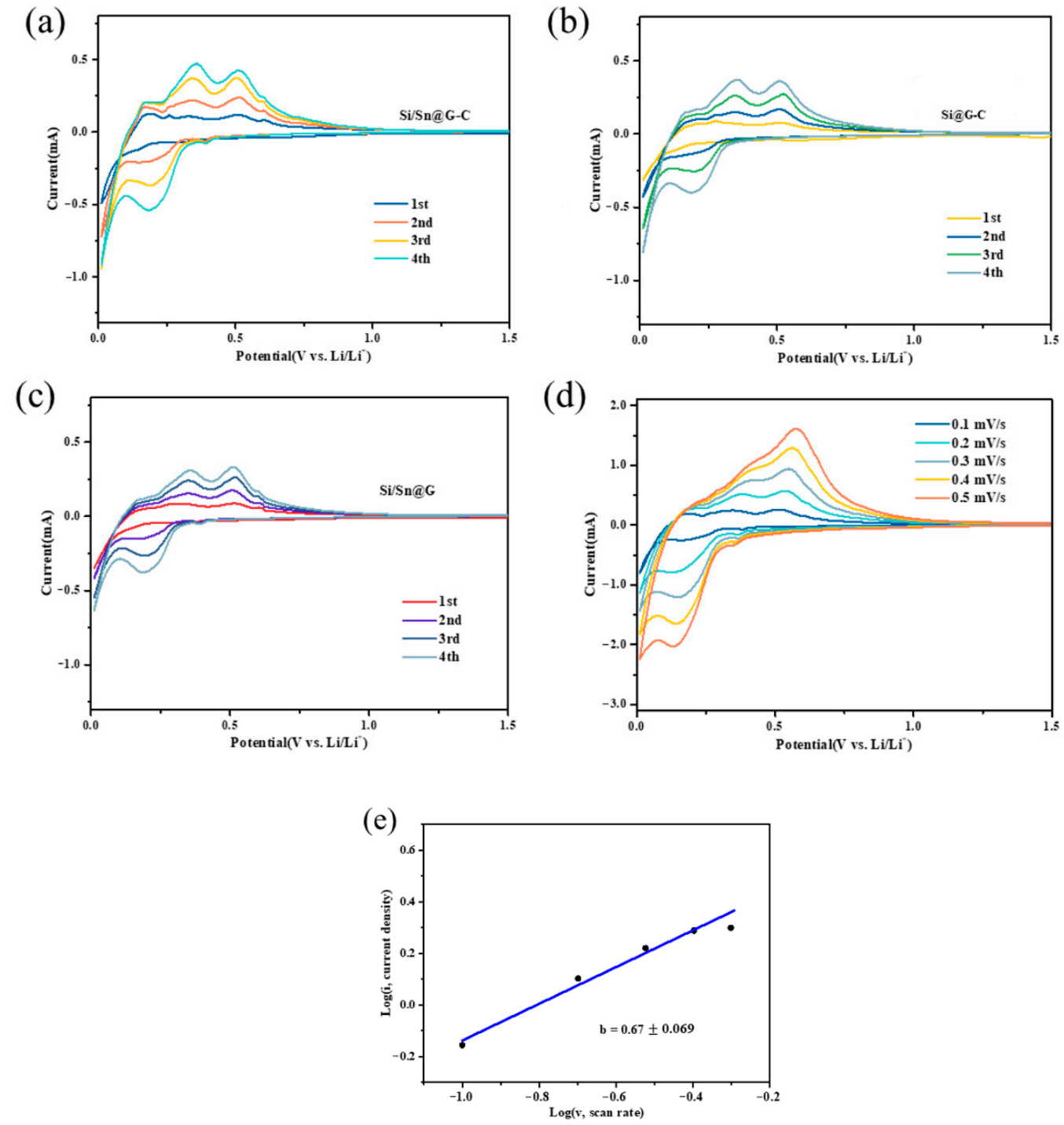

Figure 6. CV curves of the initial four cycles of (a) Si/Sn@G-C, (b) Si@G-C, (c) Si/Sn@G anode at a scan rate of $0.1 \mathrm{mV} \mathrm{s}{ }^{-1}$ with a potential range from $0.01-1.5 \mathrm{~V}$ vs. $\mathrm{Li} / \mathrm{Li}^{+}$and (d) $\mathrm{CV}$ curves of $\mathrm{Si} / \mathrm{Sn} @ \mathrm{G}-\mathrm{C}$ composite at different scanning rates; (e) $\log (\mathrm{i}) / \log (\mathrm{v})$ plots of $\mathrm{Si} / \mathrm{Sn} @ \mathrm{G}-\mathrm{C}$ at various scan rates from 0.1 to $0.5 \mathrm{mV} \mathrm{s}^{-1}$.

The CV curves of Si/Sn@G-C composite at scanning rates from 0.1 to $0.5 \mathrm{mV} \mathrm{s}^{-1}$ are shown in Figure 6d. As the scanning rate increases, the oxidation and reduction current densities increase at the same time. The polarization voltage increases slightly along with the increasing of scanning rate, but obvious reduction and oxidation peaks can be observed, which is because faster scanning rate results in more severe electrode polarization, therefore, increases the irreversibility of active materials [16]. The relationship between the peak current $(i)$ and the scan rate $(v)$ can be described as $i=a v^{b}$, where $a$ and $b$ are adjustable parameters. Parameter $b$ can be calculated by the slope of the fitted line $\lg i$ versus $\lg v$, and it reflects the main influence factor of the electrochemical reaction, $b=0.5$ means that electrochemical reaction is controlled by solid-state diffusion, while $b=1$ indicates that the reaction is dominated by surface reactions [65]. In our work, the $\lg i$ and $\lg v$ in the state of oxidation provides a $b$ value of 0.67 with a standard error of 0.069 (Figure 6e), showing a diffusion-dominated lithium-storage mechanism.

In order to further testify the positive effect of nano-Sn and amorphous carbon to the electrochemical properties of $\mathrm{Si}$, we performed electrochemical impedance spectroscopy (EIS) measurements (Figure 7). Figure 7a displays the Nyquist plots of the composites before cycles, the semicircle at high frequency region and the straight lines at low frequency 
region are ascribed to the resistance of charge transfer $\left(R_{c t}\right)$ and solid-state diffusion of lithium ions, respectively. The value of $\mathrm{R}_{\mathrm{ct}}$ of the Si/Sn@G-C, Si@G-C and Si/Sn@G anodes before cycling is 170, 266 and $335 \Omega$, respectively. The reduced electrochemical impedance of Si/Sn@G-C can be attributed to the kinetics improvement by highly conductive nano-Sn and connection enhancement by flexile amorphous carbon $[16,44]$. The fitted $R_{\mathrm{ct}}$ values of the electrodes after 200 cycles is 30,63 and $50 \Omega$ respectively, which indicates that an activation process occurs during cycles and the Si/Sn@G-C electrode has excellent structural stability during cycle.
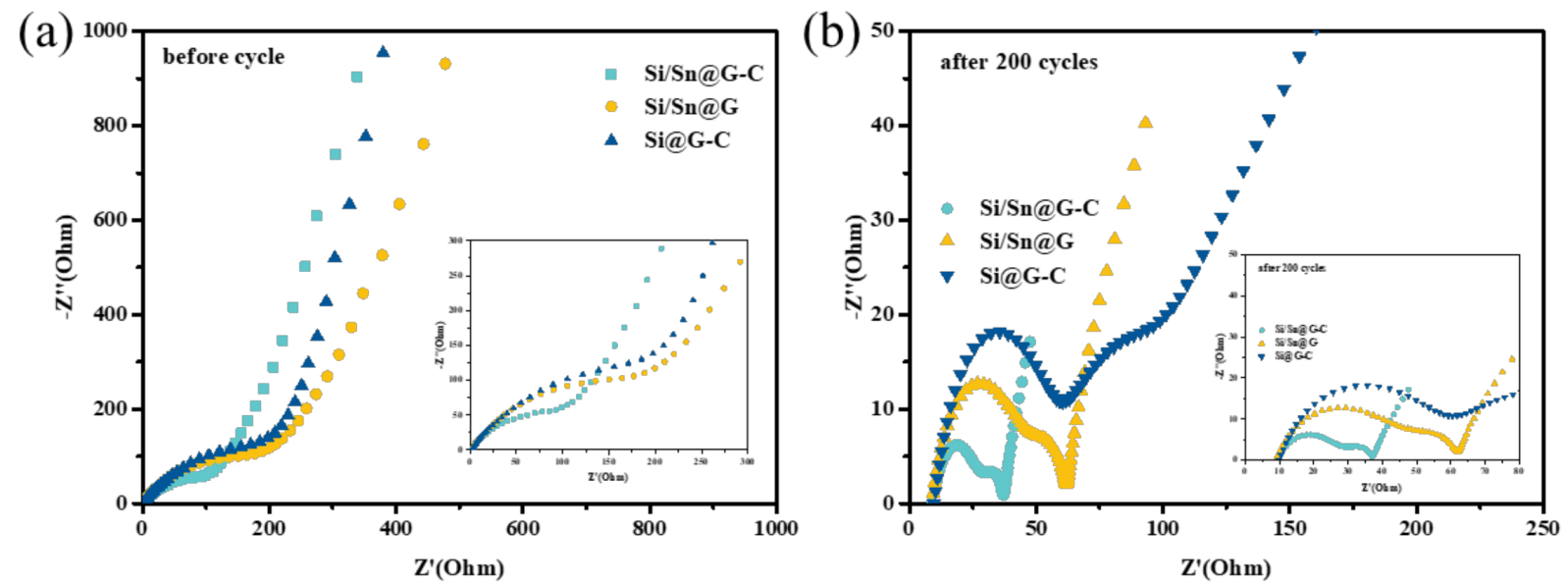

Figure 7. The Nyquist plots of the composites (a) before cycling and (b) after 100 cycles.

To further observe the change of the as prepared electrodes before and after cycles, the SEM are carried out. Figure 8a-c show the SEM images of electrodes before cycles, it is obviously that all the electrodes have a porous morphology. After 200 cycles, the morphology of the Si/Sn@G-C electrode remains intact (Figure 8d), showing the outstanding structure stability. On the contrary, many cracks can be observed on the electrode of $\mathrm{Si} / \mathrm{Sn} @ \mathrm{G}$ and Si@G-C (Figure 8e,f), which are possibly attributed to the stress accumulation of Si during the processes of charge/discharge and these cracks will lead to bad electrical contact between active materials and the current collector, resulting in a poor electrochemical performance. This result also demonstrates the reasonable design of Si/Sn@G-C composite toward high-performance LIBs.
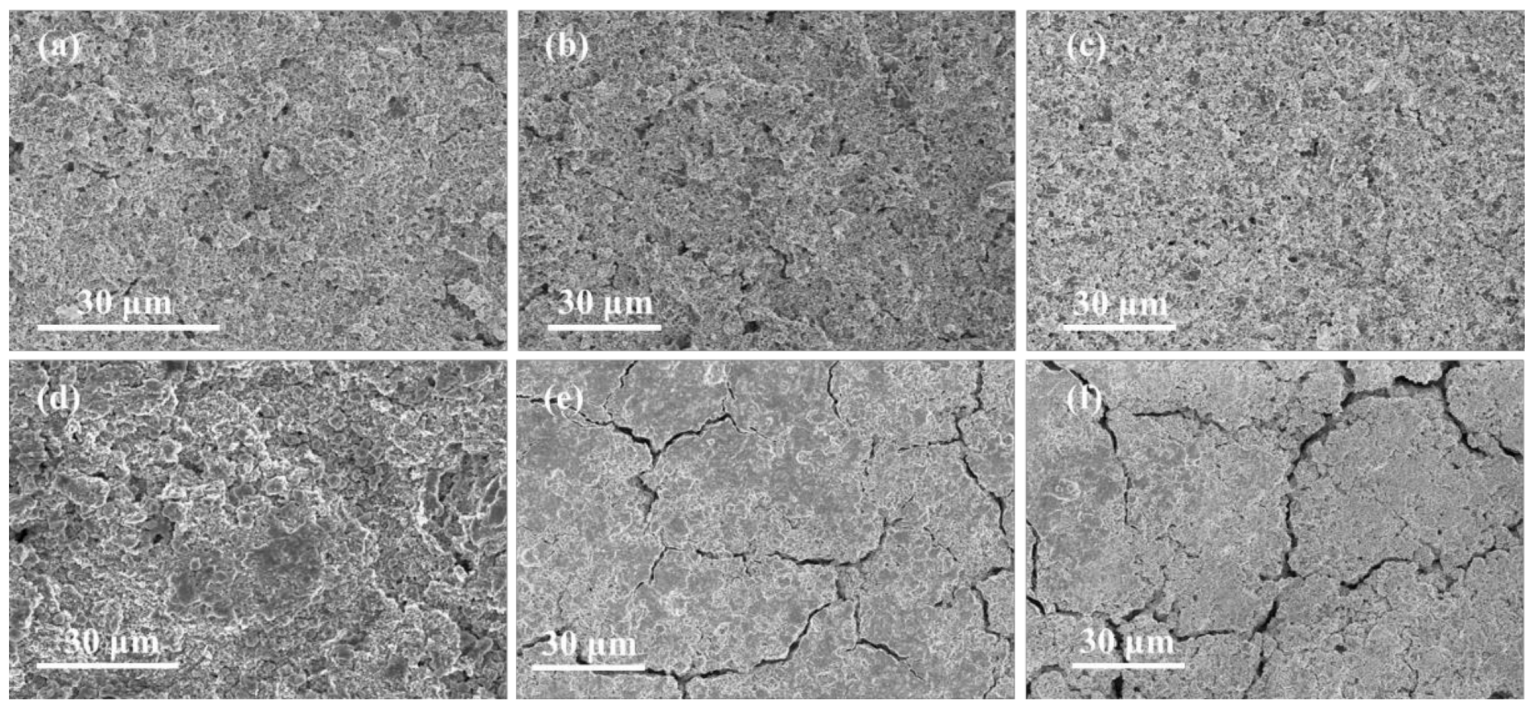

Figure 8. SEM pictures of the electrodes (a) Si/Sn@G-C, (b) Si@G-C, (c) Si/Sn@G before and (d) Si/Sn@G-C, (e) Si@G-C, (f) $\mathrm{Si} / \mathrm{Sn} @ \mathrm{G}$ after 200 charge/discharge cycles at $1 \mathrm{~A} \mathrm{~g}^{-1}$. 


\section{Conclusions}

In conclusion, the $\mathrm{Si} / \mathrm{Sn} @ \mathrm{G}-\mathrm{C}$ composite is synthesized using the micro-sized porous $\mathrm{Si}$, off-the-shelf additive including tin dichloride, PVA and graphite. The morphology property, structure and electrochemical performance of the composite are studied systematically. The pores in micro-sized porous $\mathrm{Si}$ can relieve the volume expansion during cycles and provide the transport routes for $\mathrm{Li}^{+}$. In addition, the surface-decorated nano-Sn and composited graphite can obviously decrease the electrical resistance of the composite, facilitating the lithiation of the silicon and contributes to the total energy storage capacity of the anode. Furthermore, the amorphous carbon can work as outerwear and bridging agent, prevents the silicon particles from separation by provide effective constrain force and is beneficial for the transmission of electrons, as well as promoting the formation of stable SEI layer. As a result, the Si/Sn@G-C composite shows outstanding cycle and rate performance. It delivers a reversible specific capacity of $1164 \mathrm{mAh} \mathrm{g}^{-1}$ at $1 \mathrm{~A} \mathrm{~g}^{-1}$ and maintains $825.5 \mathrm{mAh} \mathrm{g}^{-1}$ after 300 cycles, and it also exhibits excellent rate performance of $445 \mathrm{mAh} \mathrm{g}^{-1}$ at $5 \mathrm{~A} \mathrm{~g}^{-1}$. This work gives a facile and effective approach to fabricate the Si/Sn@G-C composite with satisfied performance, which will provide reference for the synthesis of next-generation Si-based anode materials.

Supplementary Materials: The following are available online at https://www.mdpi.com/1996-1 944/14/4/920/s1, Figure S1: XRD pattern of (a) porous Si, (b) graphite, Figure S2: TGA curve of Si-Sn@G-C composite, Table S1: Comparison of electrochemical performance of Si based anodes in literature, Figure S3: XRD pattern of (a) Si-Sn composite (b) Si/Sn@G composite and (c) Si@G-C composite, Table S2: The corresponding elemental contents of the EDS of Si/Sn@G-C composite in Figure 2f-I, Figure S4: Top-down SEM of $(a, b)$ the graphite (c, d) porous Si (e) Si@G-C composite, (f) Si/Sn@G composite, Figure S5: The BET results of the Si/Sn@G (a,) The N2 absorption and desorption curves of the composites and (b) the corresponding pore size distribution, Figure S6: The BET results of the $\mathrm{Si} @ \mathrm{G}-\mathrm{C}(\mathrm{a}$,$) The N2 absorption and desorption curves of the composites$ and (b) the corresponding pore size distribution, Figure S7: Electrochemical of micro sized porous $\mathrm{Si}$ (a) the charge/discharge profiles (b) the rate performance (c) the cycle performance, Figure S8: cycling performance at a current density of $0.5 \mathrm{Ag}-1$ of Si/Sn@G-C, Si@G-C and Si/Sn@G anode, Table S1: Comparison of electrochemical performance of Si based anodes in literature, Table S2: The corresponding elemental contents of the EDS of Si/Sn@G-C composite in Figure 2f-i.

Author Contributions: Conceptualization, T.Y.; methodology, T.Y., W.-Q.H.; formal analysis, S.Z. and H.Y.; investigation, J.W.; data curation, Z.Z. and J.W.; writing-original draft preparation, T.Y., Z.Z.; writing-review and edition, T.Y. and S.Z.; supervision, W.-Q.H. and H.Y. All authors have read and agreed to the published version of the manuscript.

Funding: This work has received financial support from the National Natural Science Foundation of China [Grant No. 51901206] and Taihu Electric Corporation [\#0001].

Institutional Review Board Statement: Not applicable.

Informed Consent Statement: Not applicable.

Data Availability Statement: The data presented in this study are available on request from the corresponding author.

Conflicts of Interest: The authors declare no conflict of interests.

\section{References}

1. Yu, J.; Sun, T.; Yang, Q.; Ma, J. Porous carbon networks containing Si and $\mathrm{SnO} 2$ as high performance anode materials for lithium-ion batteries. Mater. Lett. 2016, 184, 169-172. [CrossRef]

2. He, H.; Fu, W.; Wang, H.; Wang, H.; Jin, C.; Fan, H.J.; Liu, Z. Silica-modified SnO 2 -graphene "slime" for self-enhanced li-ion battery anode. Nano Energy 2017, 34, 449-455. [CrossRef]

3. Zhang, H.; Hu, R.; Liu, Y.; Cheng, X.; Liu, J.; Lu, Z.; Zeng, M.; Yang, L.; Liu, J.; Zhu, M. Highly reversible conversion reaction in Sn2Fe@SiOx nanocomposite: A high initial Coulombic efficiency and long lifetime anode for lithium storage. Energy Storage Mater. 2018, 13, 257-266. [CrossRef] 
4. Ma, T.; Yu, X.; Li, H.; Zhang, W.; Cheng, X.; Zhu, W.; Qiu, X. High Volumetric Capacity of Hollow Structured SnO2@Si Nanospheres for Lithium-Ion Batteries. Nano Lett. 2017, 17, 3959-3964. [CrossRef]

5. Hu, R.; Zhang, H.; Lu, Z.; Liu, J.; Zeng, M.; Yang, L.; Yuan, B.; Zhu, M. Unveiling critical size of coarsened Sn nanograins for achieving high round-trip efficiency of reversible conversion reaction in lithiated SnO2 nanocrystals. Nano Energy 2018, 45, 255-265. [CrossRef]

6. Zhang, S.; Ying, H.; Yuan, B.; Hu, R.; Han, W.-Q. Partial Atomic Tin Nanocomplex Pillared Few-Layered Ti3C2Tx MXenes for Superior Lithium-Ion Storage. Nano-Micro Lett. 2020, 12, 1-14. [CrossRef]

7. Zhang, S.; Huang, P.; Wang, J.; Zhuang, Z.; Zhang, Z.; Han, W.Q. Fast and Universal Solution-Phase Flocculation Strategy for Scalable Synthesis of Various Few-Layered MXene Powders. J. Phys. Chem. Lett. 2020, 11, 1247-1254. [CrossRef] [PubMed]

8. Jin, Y.; Tan, Y.; Hu, X.; Zhu, B.; Zheng, Q.; Zhang, Z.; Zhu, G.; Yu, Q.; Jin, Z.; Zhu, J. Scalable Production of the Silicon-Tin Yin-Yang Hybrid Structure with Graphene Coating for High Performance Lithium-Ion Battery Anodes. ACS Appl. Mater. Interfaces 2017, 9, 15388-15393. [CrossRef] [PubMed]

9. Vernardou, D.; Marathianou, I.; Katsarakis, N.; Koudoumas, E.; Kazadojev, I.I.; O’Brien, S.; Pemble, M.E.; Povey, I.M. Capacitive behavior of Ag doped V2O5 grown by aerosol assisted chemical vapour deposition. Electrochim. Acta 2016, 196, 294-299. [CrossRef]

10. Li, X.; Zhang, M.; Yuan, S.; Lu, C. Research Progress of Silicon/Carbon Anode Materials for Lithium-Ion Batteries: Structure Design and Synthesis Method. ChemElectroChem 2020, 7, 4289-4302. [CrossRef]

11. Zhao, J.; Zhou, G.; Yan, K.; Xie, J.; Li, Y.; Liao, L.; Jin, Y.; Liu, K.; Hsu, P.C.; Wang, J.; et al. Air-stable and freestanding lithium alloy/graphene foil as an alternative to lithium metal anodes. Nat. Nanotechnol. 2017, 12, 993-999. [CrossRef]

12. Tian, H.; Tan, X.; Xin, F.; Wang, C.; Han, W. Micro-sized nano-porous Si/C anodes for lithium ion batteries. Nano Energy 2015, 11, 490-499. [CrossRef]

13. Chae, S.; Choi, S.-H.; Kim, N.; Sung, J.; Cho, J. Integration of Graphite and Silicon Anodes for the Commercialization of High-Energy Lithium-Ion Batteries. Angew. Chem. Int. Ed. 2020, 59, 110-135. [CrossRef]

14. Yi, Z.; Wang, W.; Qian, Y.; Liu, X.; Lin, N.; Qian, Y. Mechanical Pressing Route for Scalable Preparation of Microstructured/Nanostrutured Si/Graphite Composite for Lithium Ion Battery Anodes. ACS Sustain. Chem. Eng. 2018, 6, 14230-14238. [CrossRef]

15. Zheng, Y.; Yang, J.; Tao, L.; Nuli, Y.-N.; Wang, J.-L. Study of nano-porous Si/Graphite/C composite anode materials for Li-ion batteries. Chin. J. Inorg. Chem. 2007, 23, 1882-1886.

16. Yang, D.; Shi, J.; Shi, J.; Yang, H. Simple synthesis of Si/Sn@C-G anodes with enhanced electrochemical properties for Li-ion batteries. Electrochim. Acta 2018, 259, 1081-1088. [CrossRef]

17. Pei, Y.; Wang, S.; Zhou, Q.; Xie, S.-H.; Qiao, M.-H.; Jiang, Z.-Y.; Fan, K.-N. Single crystalline SnO nanosheets as anode material for lithium secondary battery. Chin. J. Chem. 2007, 25, 1385-1388. [CrossRef]

18. Song, J.-S.; Cho, G.-B.; Ahn, H.-J.; Kim, H.-S.; Ahn, J.-H.; Cho, K.-K. Electrochemical Performance of Sn/SnO Nanoparticles with Core-Shell Structure as Anode Materials for Sodium-Ion and Lithium-Ion Batteries. J. Nanosci. Nanotechnol. 2016, 16, 10735-10739. [CrossRef]

19. Wang, F.; Liu, C.; Zhang, J.; Cao, L. Research status and prospect of TiO_2 anode materials for lithium-ion batteries. Chinese J. Power Sources 2018, 42, 301-303.

20. Liu, Q.; Dou, Y.; Ruan, B.; Sun, Z.; Chou, S.-L.; Dou, S.X. Carbon-Coated Hierarchical SnO2 Hollow Spheres for Lithium Ion Batteries. Chem. -A Eur. J. 2016, 22, 5853-5857. [CrossRef]

21. Wang, L.; Chen, Q.; Zhu, Y.; Qian, Y. Graphene-wrapped $\mathrm{Fe}_{2} \mathrm{O}_{3}$ nanorings for Li ion battery anodes. Chin. Sci. Bull. 2014, 59, 4271-4273. [CrossRef]

22. Liu, B.; Chuang, Y.; Zhang, Y.A.J.; Chen, H.; Hayat, T.; Alsaedi, A.; Ahmad, B. The Preparation of CuO@ZnO Core-Shell Materials as High-Stability Anodes for Lithium-Ion Batteries. Int. J. Electrochem. Sci. 2019, 14, 8973-8985. [CrossRef]

23. Li, H.; Huang, X.J.; Chen, L.Q. Electrochemical impedance spectroscopy study of SnO and nano-SnO anodes in lithium rechargeable batteries. J. Power Sources 1999, 81, 340-345. [CrossRef]

24. Yang, H.; Liang, K.; Du, J.; Tian, L.; Wen, X. Facile preparation of nanoscale silicon as anode materials for lithium ion batteries by a mild temperature metathesis route. Electron. Compon. Mater. 2017, 36, $43-47$.

25. Zhang, Y.; Liu, H. Research Progress on Si / C Composite Anode Materials for Lithium-ion Battery. Bull. Chin. Ceram. Soc. 2015, 34, 989-994.

26. He, X.; Pu, W.; Ren, J.; Wang, L.; Jiang, C.; Wan, C. Synthesis of nanosized Si composite anode material for Li-ion batteries. Ionics 2007, 13, 51-54. [CrossRef]

27. Wang, G.X.; Ahn, J.H.; Yao, J.; Bewlay, S.; Liu, H.K. Nanostructured Si-C composite anodes for lithium-ion batteries. Electrochem. Commun. 2004, 6, 689-692. [CrossRef]

28. Jia, D.; Li, X.; Huang, J. A Hierarchical, Nanofibrous, Tin-Oxide/Silicon Composite Derived from Cellulose as a High-Performance Anode Material for Lithium-Ion Batteries. ChemistrySelect 2017, 2, 5667-5676. [CrossRef]

29. Wang, X.; Wen, Z.; Liu, Y.; Huang, L.; Wu, M. Study on Si-Ti alloy dispersed in a glassy matrix as an anode material for lithium-ion batteries. J. Alloys Compd. 2010, 506, 317-322. [CrossRef]

30. Wang, S.; Liao, J.; Wu, M.; Xu, Z.; Gong, F.; Chen, C.; Wang, Y.; Yan, X. High Rate and Long Cycle Life of a CNT/rGO/Si Nanoparticle Composite Anode for Lithium-Ion Batteries. Part. Part. Syst. Charact. 2017, 34. [CrossRef] 
31. Zhou, M.; Cai, T.; Pu, F.; Chen, H.; Wang, Z.; Zhang, H.; Guan, S. Graphene/Carbon-Coated Si Nanoparticle Hybrids as High-Performance Anode Materials for Li-Ion Batteries. ACS Appl. Mater. Interfaces 2013, 5, 3449-3455. [CrossRef]

32. Liu, J.L.; Cai, S.J.; Jin, G.L.; Tang, Y.S.; Wang, K.L. Gas-source MBE growth of freestanding Si nano-wires on Au/Si substrate. Superlattices Microstruct. 1999, 25, 477-479. [CrossRef]

33. Hu, L.; Wu, H.; Hong, S.S.; Cui, L.; McDonough, J.R.; Bohy, S.; Cui, Y. Si nanoparticle-decorated Si nanowire networks for Li-ion battery anodes. Chem. Commun. 2011, 47, 367-369. [CrossRef]

34. Ren, W.; Wang, C.; Lu, L.; Li, D.; Cheng, C.; Liu, J. SnO2@Si core-shell nanowire arrays on carbon cloth as a flexible anode for Li ion batteries. J. Mater. Chem. A 2013, 1, 13433-13438. [CrossRef]

35. Hao, Q.; Hou, J.; Ye, J.; Yang, H.; Du, J.; Xu, C. Hierarchical macroporous Si/Sn composite: Easy preparation and optimized performances towards lithium storage. Electrochim. Acta 2019, 306, 427-436. [CrossRef]

36. Kim, M.G.; Yun, Z.; Lyou, J.; Cho, S.; Park, Y.J.; Kim, E.K. Visible photoluminescence from porous poly-Si/Si and amorphous-Si/Si structures. J. Korean Phys. Soc. 2001, 38, 750-753.

37. Huang, T.; Sun, D.; Yang, W.; Wu, Q.; Xiao, R. The Fabrication of Porous Si with Interconnected Micro-Sized Dendrites and Tunable Morphology through the Dealloying of a Laser Remelted Al-Si Alloy. Materials 2017, 10, 357. [CrossRef]

38. Fang, R.; Xiao, W.; Miao, C.; Mei, P.; Yan, X.; Zhang, Y.; Jiang, Y. Improved lithium storage performance of pomegranate-like $\mathrm{Si@NC/rGO}$ composite anodes by facile in-situ nitrogen doped carbon coating and freeze drying processes. J. Alloys Compd. 2020, 834, 155230. [CrossRef]

39. Yang, W.; Ying, H.; Zhang, S.; Guo, R.; Wang, J.; Han, W.-Q. Electrochemical performance enhancement of porous Si lithium-ion battery anode by integrating with optimized carbonaceous materials. Electrochim. Acta 2020, 337, 135687. [CrossRef]

40. Autthawong, T.; Namsar, O.; Yu, A.; Sarakonsri, T. Cost-effective production of $\mathrm{SiO} 2 / \mathrm{C}$ and $\mathrm{Si} / \mathrm{C}$ composites derived from rice husk for advanced lithium-ion battery anodes. J. Mater. Sci. Mater. Electron. 2020, 31, 9126-9132. [CrossRef]

41. Xia, K.; Qu, L.; Liu, X.; Han, H.; Hou, Z.; Li, Y.; Deng, S. Effect of SnCl2 addition on the structure and lithium storage performance of SiOC anodes. Appl. Surf. Sci. 2020, 506, 144775. [CrossRef]

42. Su, L.; Zhou, Z.; Ren, M. Core double-shell Si@SiO2@C nanocomposites as anode materials for Li-ion batteries. Chem. Commun. (Camb) 2010, 46, 2590-2592. [CrossRef]

43. Wu, W.; Wang, M.; Wang, J.; Wang, C.; Deng, Y. Green Design of Si/SiO2/C Composites as High-Performance Anodes for Lithium-Ion Batteries. ACS Appl. Energy Mater. 2020, 3, 3884-3892. [CrossRef]

44. Zhong, L.; Beaudette, C.; Guo, J.; Bozhilov, K.; Mangolini, L. Tin nanoparticles as an effective conductive additive in silicon anodes. Sci. Rep. 2016, 6, 30952. [CrossRef]

45. Hassoun, J.; Panero, S.; Mulas, G.; Scrosati, B. An electrochemical investigation of a Sn-Co-C ternary alloy as a negative electrode in Li-ion batteries. J. Power Sources 2007, 171, 928-931. [CrossRef]

46. Zhang, J.; Liang, Y.; Zhou, Q.; Peng, Y.; Yang, H. Enhancing electrochemical properties of silicon-graphite anodes by the introduction of cobalt for lithium-ion batteries. J. Power Sources 2015, 290, 71-79. [CrossRef]

47. Hao, Q.; Zhao, D.; Duan, H.; Zhou, Q.; Xu, C. Si/Ag composite with bimodal micro-nano porous structure as a high-performance anode for Li-ion batteries. Nanoscale 2015, 7, 5320-5327. [CrossRef]

48. Wu, X.D.; Wang, Z.X.; Chen, L.Q.; Huang, X.J. Ag-enhanced SEI formation on Si particles for lithium batteries. Electrochem. Commun. 2003, 5, 935-939. [CrossRef]

49. Guojun, Z.; Naigen, H. Synthesis and Properties of Si/Ag and Si/Ag/CMS Composites as Anode Materials for Li-ion Batteries. Silicon 2019, 11, 2517-2520. [CrossRef]

50. Park, M.-S.; Rajendran, S.; Kang, Y.-M.; Han, K.-S.; Han, Y.-S.; Lee, J.-Y. Si-Ni alloy-graphite composite synthesized by arc-melting and high-energy mechanical milling for use as an anode in lithium-ion batteries. J. Power Sources 2006, 158, 650-653. [CrossRef]

51. Kim, B.C.; Uono, H.; Satou, T.; Fuse, T.; Ishihara, T.; Ue, M.; Senna, M. Cyclic properties of Si-Cu/carbon nanocomposite anodes for Li-ion secondary batteries. J. Electrochem. Soc. 2005, 152, A523-A526. [CrossRef]

52. Kang, Y.-M.; Park, M.-S.; Lee, J.-Y.; Liu, H.-K. Si-Cu/carbon composites with a core-shell structure for Li-ion secondary battery. Carbon 2007, 45, 1928-1933. [CrossRef]

53. Yoon, S.; Lee, S.-I.; Kim, H.; Sohn, H.-J. Enhancement of capacity of carbon-coated Si-Cu3Si composite anode using metal-organic compound for lithium-ion batteries. J. Power Sources 2006, 161, 1319-1323. [CrossRef]

54. Zhao, W.; Du, N.; Xiao, C.; Wu, H.; Zhang, H.; Yang, D. Large-scale synthesis of Ag-Si core-shell nanowall arrays as highperformance anode materials of Li-ion batteries. J. Mater. Chem. A 2014, 2, 13949-13954. [CrossRef]

55. Li, C.; Zhang, P.; Jiang, Z. Effect of nano Cu coating on porous Si prepared by acid etching Al-Si alloy powder. Electrochim. Acta 2015, 161, 408-412. [CrossRef]

56. Liu, X.; Gao, Y.; Jin, R.; Luo, H.; Peng, P.; Liu, Y. Scalable synthesis of Si nanostructures by low-temperature magnesiothermic reduction of silica for application in lithium ion batteries. Nano Energy 2014, 4, 31-38. [CrossRef]

57. Kim, H.; Seo, M.; Park, M.H.; Cho, J. A critical size of silicon nano-anodes for lithium rechargeable batteries. Angew. Chem. Int. Ed. Engl. 2010, 49, 2146-2149. [CrossRef] [PubMed]

58. Tian, H.; Xin, F.; Wang, X.; He, W.; Han, W. High capacity group-IV elements (Si, Ge, Sn) based anodes for lithium-ion batteries. J. Mater. 2015, 1, 153-169. [CrossRef]

59. Liu, D.; Liu, Z.J.; Li, X.; Xie, W.; Wang, Q.; Liu, Q.; Fu, Y.; He, D. Group IVA Element (Si, Ge, Sn)-Based Alloying/Dealloying Anodes as Negative Electrodes for Full-Cell Lithium-Ion Batteries. Small 2017, 13, 13. [CrossRef] 
60. He, W.; Tian, H.; Xin, F.; Han, W. Scalable fabrication of micro-sized bulk porous Si from Fe-Si alloy as a high performance anode for lithium-ion batteries. J. Mater. Chem. A 2015, 3, 17956-17962. [CrossRef]

61. Fang, G. A Hybrid Si@C@CNT@C Anode by Anchoring Silicon Nanoparticles onto CNT for Enhancing Performance in Lithium Ion Battery. Int. J. Electrochem. Sci. 2019, 10, 1580-1590. [CrossRef]

62. Han, W.Q.; Zettl, A. Coating single-walled carbon nanotubes with tin oxide. Nano Lett. 2003, 3, 681-683. [CrossRef]

63. Zhao, D.; Li, P. Penetrating needling from Qiuxu (GB 40) to Zhaohai (KI 6) for 30 cases of palpitation. Zhongguo zhen jiu = Chin. Acupunct. Moxibustion 2014, 34.

64. Vogl, U.S.; Lux, S.F.; Das, P.; Weber, A.; Placke, T.; Kostecki, R.; Winter, M. The Mechanism of SEI Formation on Single Crystal $\mathrm{Si}(100), \mathrm{Si}(110)$ and $\mathrm{Si}(111)$ Electrodes. J. Electrochem. Soc. 2015, 162, A2281-A2288. [CrossRef]

65. Li, P.; Hwang, J.Y.; Sun, Y.K. Nano/Microstructured Silicon-Graphite Composite Anode for High-Energy-Density Li-Ion Battery. ACS Nano 2019, 13, 2624-2633. [CrossRef] [PubMed] 